\title{
Preparation of an aluminium phosphate binder and its influence on the bonding strength of coating
}

\author{
YIZHEN LI ${ }^{1,2}$ (1), GUOCHAO CHEN ${ }^{1,2}$, SHIZHEN ZHU ${ }^{1,2, *}$, HEZHANG LI ${ }^{1,2}$, ZHUANG MA ${ }^{1,2}$, \\ YANBO LIU ${ }^{1,2}$ and LING LIU ${ }^{1,2}$ \\ ${ }^{1}$ School of Materials Science and Engineering, Beijing Institute of Technology, Beijing 100081, People's Republic of \\ China \\ ${ }^{2}$ National Key Laboratory of Science and Technology on Materials under Shock and Impact, Beijing 100081, People's \\ Republic of China \\ *Author for correspondence (zhusz@bit.edu.cn)
}

MS received 9 August 2018; accepted 13 April 2019

\begin{abstract}
In this paper, aluminium phosphate binders were synthesized using $\mathrm{Al}(\mathrm{OH})_{3}$ and $\mathrm{H}_{3} \mathrm{PO}_{4}$ as the raw materials. These binders, with the curing agent $\mathrm{MgO}$ and filler $\mathrm{ZrO}_{2}$, were used to prepare coatings by brush painting on the carbon fibre-reinforced epoxy resin matrix composites. The influences of synthesis conditions such as the $\mathrm{P} / \mathrm{Al}$ ratio, concentration of the reactant and reaction temperature on the viscosity of binders and the bonding strength of corresponding coatings were investigated by using a viscometer and a universal testing machine. The structures and compositions of aluminium phosphate binders were characterized by X-ray diffraction, Fourier transform infrared and Raman spectroscopy. The results show that with a decrease in the ratio of $\mathrm{P} / \mathrm{Al}$, the degree of polymerization of the aluminium phosphate binder increases, the viscosity increases, while the bonding strength of the coating decreases. When $\mathrm{P} / \mathrm{Al}=3: 1$, the reaction product is $\mathrm{Al}\left(\mathrm{H}_{2} \mathrm{PO}_{4}\right)_{3}$ with the best properties of bonding strength. As the concentration of phosphoric acid solution increases in the range of $60-80 \%$, the viscosity increases on account of larger quantity of viscous molecules in a unit volume and higher extent of polymerization of the phosphorus oxygen tetrahedron. The compositions of aluminium phosphate binders are almost the same when the reaction temperature changes from 120 to $180^{\circ} \mathrm{C}$, so the viscosity of the binder and the bonding strength of the coating do not exhibit obvious changes along with temperature.
\end{abstract}

Keywords. Aluminium phosphate binder; coating; viscosity; bonding strength; P/Al mole ratio; concentration.

\section{Introduction}

The carbon fibre-reinforced epoxy composite has many advantages, such as high-specific strength, strong fatigue resistance and corrosion resistance. Though it is widely used in the fields of aerospace, automotive and wind power [1-3], its poor temperature tolerance restricts its wide application. The phosphate binder can be cured into a film at low-temperature and it has a high-bonding strength at hightemperature. It can not only bond metal, ceramics and organic materials [4-7], but can also be used as the base material to prepare composite materials and various protective coatings to enhance the mechanical properties and protecting ability of materials in special environments such as high-temperature and high-energy and expand the application range of organic composite materials [8-13].

The $\mathrm{P} / \mathrm{M}$ mole ratio and the concentration of the phosphoric acid solution are two important parameters that affect the properties of the phosphate binder. The P/M mole ratio represents the molar ratio of the phosphorus atom to the metal cation in the binder. Besides, the preparation temperature also has an influence on the properties of the binder. He et al [14] showed that the main component of the synthetic phosphate binder is $\mathrm{Al}\left(\mathrm{H}_{2} \mathrm{PO}_{4}\right)_{3}$ when $\mathrm{P} / \mathrm{Al}=3: 1.4$ and the reaction temperature is $200^{\circ} \mathrm{C}$; Femando et al [11] indicated that the binder properties are better when the $\mathrm{P} / \mathrm{Al}$ mole ratio is $3: 1.2$ and the reaction temperature is $150^{\circ} \mathrm{C}$; Chiou et al [15] found that the aluminium phosphate adhesive with a P/Al molar ratio of 2.2 at $500^{\circ} \mathrm{C}$ is converted into type $\mathrm{B}$ aluminium metaphosphate, and when the molar ratio of $\mathrm{P} / \mathrm{Al}$ is 5.8 or higher, it is converted into A type aluminium metaphosphate. When heated to $800^{\circ} \mathrm{C}$, most aluminium phosphate adhesives became Type A aluminium metaphosphate. In the current literature, the thermal curing process of the phosphate binder and the structure and properties of the cured products are mainly studied. However, there are few research studies on the solution of aluminium phosphate binders. In order to optimize the process parameters for the preparation of phosphate binders and develop the coating which is suitable for the protection of resin matrix composites, in this paper, $\mathrm{H}_{3} \mathrm{PO}_{4}$ and $\mathrm{Al}(\mathrm{OH})_{3}$ were used as raw materials to prepare the aluminium phosphate binder. The reaction product and its polymerization extent under different reaction conditions (P/Al mole ratio, concentration of the reactant solution of phosphoric acid 
Table 1. Process parameters in the preparation of the aluminium phosphate binder.

\begin{tabular}{lccc}
\hline Sample & Concentration of $\mathrm{H}_{3} \mathrm{PO}_{4} /(\mathrm{wt} \%)$ & P/Al mole ratio & Temperature $/\left({ }^{\circ} \mathrm{C}\right)$ \\
\hline S1 & 60 & $3: 1$ & 150 \\
S2 & 70 & $3: 1$ & 150 \\
S3 & 80 & $3: 1$ & 150 \\
S4 & 60 & $3: 1.2$ & 150 \\
S5 & 60 & $3: 1.4$ & 150 \\
S6 & 60 & $3: 1$ & 120 \\
S7 & 60 & $3: 1$ & 180 \\
\hline
\end{tabular}

and reaction temperature) were analysed. The influence of reaction conditions on the viscosity of the binder and the bonding strength of the corresponding coatings were investigated.

\section{Experimental}

The raw materials were $\mathrm{H}_{3} \mathrm{PO}_{4}$ ( $85 \mathrm{wt} \%$, chemically pure, Beijing Chemical Reagent Co. Ltd.), $\mathrm{Al}(\mathrm{OH})_{3}$ (analytical pure, $\mathrm{Fu}$ Chen chemical reagents company), $\mathrm{Mg}(\mathrm{OH})_{2}$ (analytical pure, $\mathrm{Fu}$ Chen chemical reagents company), $\mathrm{ZrO}_{2}$ (particle size of about 2-10 $\mu \mathrm{m}$, Forsman Scientific (Beijing) Co. Ltd.) and carbon fibre-reinforced epoxy composite sheet $(\varnothing 25 \times 2.5 \mathrm{~mm})$ with surface cleaning, roughening by sandblasting.

The phosphoric acid solution of 60,70 and 80 wt $\%$ was prepared respectively by adding appropriate amounts of deionized water. Phosphoric acid was heated to $70^{\circ} \mathrm{C}$ for $10 \mathrm{~min}$, and then heated up to the setting reaction temperature. $\mathrm{Al}(\mathrm{OH})_{3}$ was slowly added to the phosphoric acid solution according to a certain P/Al mole ratio. After reacting for $30 \mathrm{~min}$, the reactants were stopped heating and cooled naturally. Then the prepared aluminium phosphate binder could be filled into the bottle for use. The experimental number and process parameters are shown in table 1 . The viscosity of the aluminium phosphate binder was measured by using a NDJ5 rotary viscometer at room temperature. The structures of aluminium phosphate binders were characterized by infrared and Raman spectroscopy using a Nicolet 6700 Fourier transform infrared spectrometer and a DXRxi microscopy Raman imaging spectrometer (532 nm laser excitation). Meanwhile, a part of the solution was pre-cured in an oven at $100^{\circ} \mathrm{C}$ for a long time, and the pre-cured phase of the binder was analysed by using a D8 advance type X-ray diffractometer made in Germany Bruker Company.

The raw materials were mixed in the ratio of $8 \mathrm{~g}$ binder, $0.6 \mathrm{~g} \mathrm{MgO}$ and $6 \mathrm{~g} \mathrm{ZrO}_{2}$, and then uniformly coated on the carbon fibre epoxy composite with $\varnothing 25 \times 2.5 \mathrm{~mm}$. In order to control the thickness of the coating, a $3 \mathrm{~mm}$ substrate was placed inside a $3.5 \mathrm{~mm}$ groove for brush painting to obtain a coating having a thickness of about $0.5 \mathrm{~mm}$. The differential scanning calorimetry (DSC) test results of the aluminium

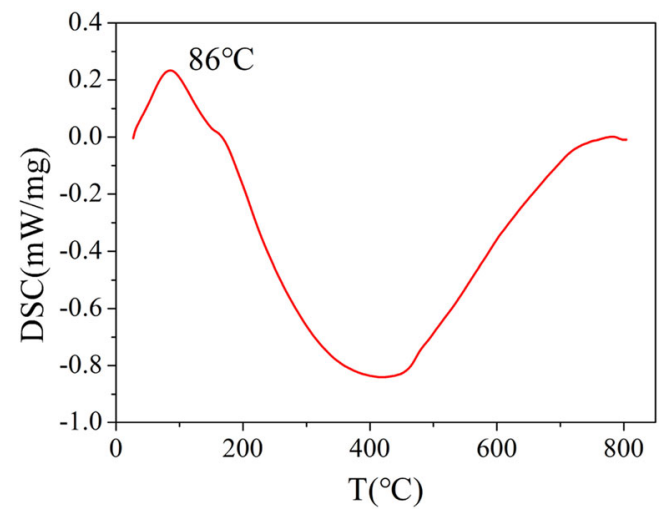

Figure 1. The DSC curve of adhesive added with $\mathrm{MgO}(\mathrm{P} / \mathrm{Al}=3)$.

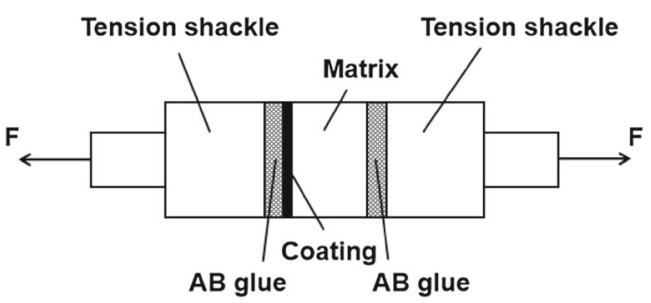

Figure 2. The stretch schematic of the bonding strength of the coating.

phosphate adhesive with $\mathrm{P} / \mathrm{Al}=3$ added with $\mathrm{MgO}$ are shown in figure 1 and the results show that there is a absorption peak at $86^{\circ} \mathrm{C}$, that is, the complete curing temperature of the aluminium phosphate adhesive with $\mathrm{MgO}$ is about $86^{\circ} \mathrm{C}$. Adding a curing agent can greatly reduce the curing temperature of the aluminium phosphate adhesive. In order to compare with the adhesive without the curing agent, the curing temperature is chosen to be $100^{\circ} \mathrm{C}$. The samples were dried at room temperature for $12 \mathrm{~h}$ and placed in a $60^{\circ} \mathrm{C}$ oven for $24 \mathrm{~h}$ and then increased the temperature to $100^{\circ} \mathrm{C}$ and maintained for $24 \mathrm{~h}$, and then tested for bonding strength according to GB/T 8642-2002. According to the standard, the cross-sectional dimensions of the slider and the sample are both $\varnothing 25 \mathrm{~mm}$. As shown in figure 2, the two ends of the sample was bonded to two sliders by $\mathrm{AB}$ glue, and then left at 


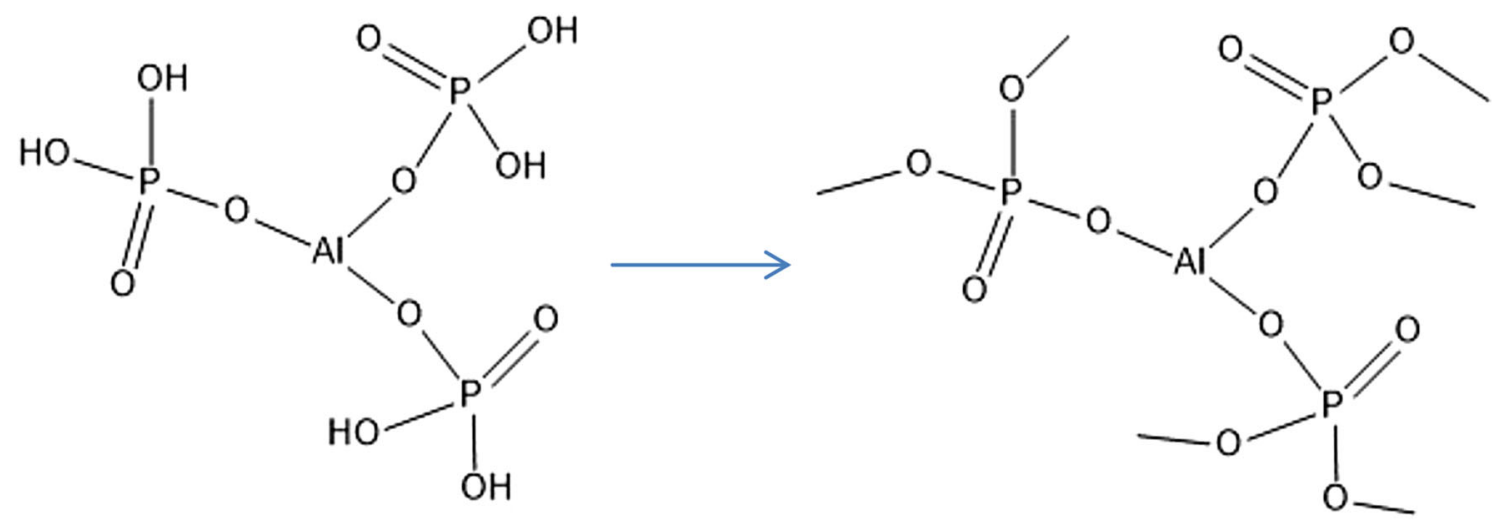

Figure 3. The polycondensation mechanism of aluminium phosphate.

room temperature for $24 \mathrm{~h}$. After the $\mathrm{AB}$ glue is completely cured, the sample bonded to the slider is mounted on an electronic universal stretching machine for a tensile test, and the ultimate load at the time of breaking is recorded. The bond strength of the coating is calculated by the following equation:

$$
\delta_{\mathrm{b}}=\frac{F}{S}
$$

where $\delta_{\mathrm{b}}$ is the bond strength of the coating, MPa; $F$ the maximum loading of the sample at break, $\mathrm{N}$ and $S$ the area of sample coating, $\mathrm{mm}^{2}$.

\section{Results and discussion}

\subsection{Effect of the P/Al mole ratio on viscosity and bonding strength}

The reaction of $\mathrm{H}_{3} \mathrm{PO}_{4}$ and $\mathrm{Al}(\mathrm{OH})_{3}$ is mainly in three forms which are shown in equations (2-4):

$$
\begin{aligned}
& 3 \mathrm{H}_{3} \mathrm{PO}_{4}+\mathrm{Al}(\mathrm{OH})_{3}=\mathrm{Al}\left(\mathrm{H}_{2} \mathrm{PO}_{4}\right)_{3}+3 \mathrm{H}_{2} \mathrm{O} \\
& 3 \mathrm{H}_{3} \mathrm{PO}_{4}+2 \mathrm{Al}(\mathrm{OH})_{3}=\mathrm{Al}_{2}\left(\mathrm{HPO}_{4}\right)_{3}+6 \mathrm{H}_{2} \mathrm{O} \\
& \mathrm{H}_{3} \mathrm{PO}_{4}+\mathrm{Al}(\mathrm{OH})_{3}=\mathrm{AlPO}_{4}+3 \mathrm{H}_{2} \mathrm{O}
\end{aligned}
$$

Phosphate can be polycondensed into macromolecules at higher temperatures to form complex three-dimensional network structures with good bonding properties. The process is shown in figure 3 (taking $\mathrm{Al}\left(\mathrm{H}_{2} \mathrm{PO}_{4}\right)_{3}$ as an example).

Figure 4 shows the results of the viscosity and bonding strength changing with the P/Al mole ratio. The viscosity of the aluminium phosphate binder increases with a decrease in the $\mathrm{P} / \mathrm{Al}$ mole ratio. When the $\mathrm{P} / \mathrm{Al}$ mole ratio increases from $3: 1.2$ to $3: 1.4$, the viscosity increases greatly. The bonding strength of the coating gradually decreases with a decrease in the P/Al mole ratio. Figure 5 shows the scanning electron microscopy (SEM) images of coatings with different

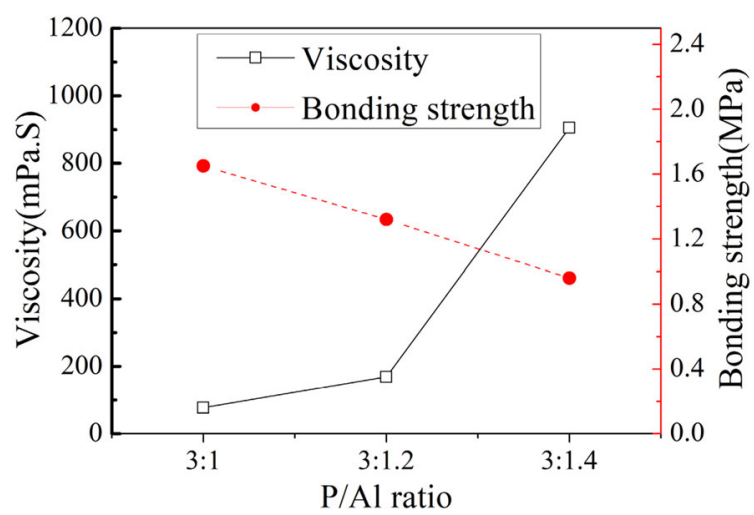

Figure 4. Viscosity and bonding strength with different $\mathrm{P} / \mathrm{Al}$ mole ratios.

$\mathrm{P} / \mathrm{Al}$ mole ratios. It can be found that as the viscosity of the adhesive increases, the surface of the cured coating gradually appears with fine protrusions, the unevenness of the coating is increased and the bonding strength decreases.

Figure 6 shows the Fourier transform infrared (FT-IR) spectra of the aluminium phosphate binder with different $\mathrm{P} / \mathrm{Al}$ mole ratios. The peaks near $3400-3200$ and $1630 \mathrm{~cm}^{-1}$ are assigned to the infrared absorption peak of water. The FTIR spectra of P/Al mole ratios of 3:1 and 3:1.2 are basically identical, and the characteristic peaks around 1100-1050 and $960 \mathrm{~cm}^{-1}$ are attributed to the absorption peaks of O-P$\mathrm{O}$ symmetric stretching vibrations and $\mathrm{P}-\mathrm{O}-\mathrm{P}$ asymmetric stretching vibrations [16-18], respectively. When the P/Al mole ratio of the aluminium phosphate binder is $3: 1.4$, the two peaks become a dispersion peak spanning $1100-900 \mathrm{~cm}^{-1}$, and the absorption intensity is also increased, which indicates that the $\mathrm{P}-\mathrm{O}$ bond stretching vibration is strengthened and the number of $\mathrm{P}-\mathrm{O}$ bonds is increased, indicating that the degree of polymerization of the binder increases. This is the reason why the viscosity increases significantly in the $\mathrm{P} / \mathrm{Al}$ mole ratio of 3:1.4. 
(a)

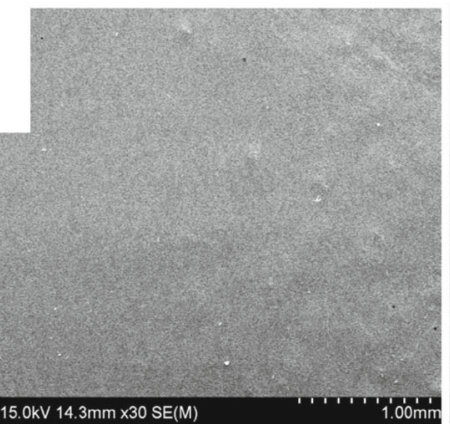

(b)

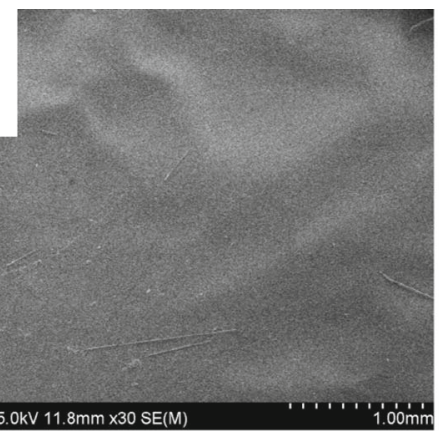

(c)

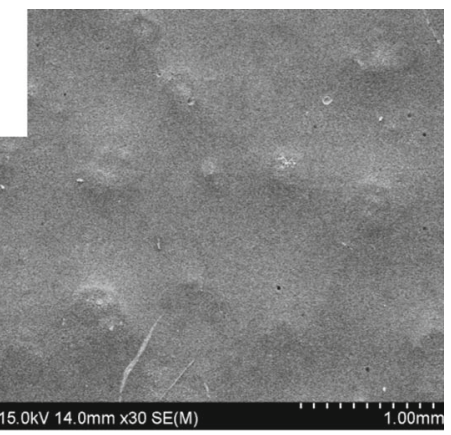

Figure 5. SEM images of coatings with different P/Al mole ratios: (a) 3:1, (b) 3:1.2 and (c) 3:1.4.

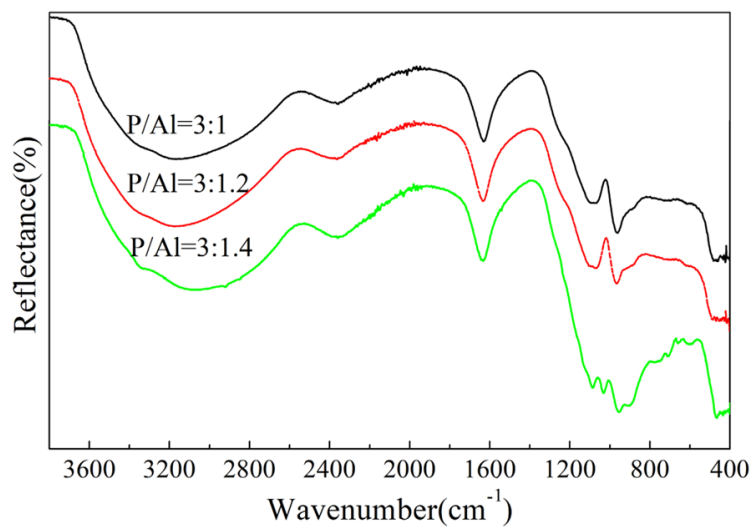

Figure 6. FT-IR spectra of the aluminium phosphate binder with different $\mathrm{P} / \mathrm{Al}$ mole ratios.

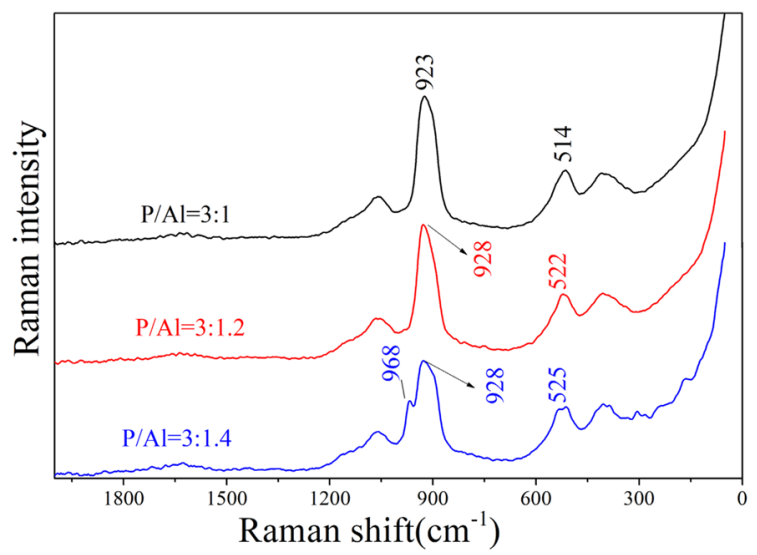

Figure 7. Raman spectra of the aluminium phosphate binder with different $\mathrm{P} / \mathrm{Al}$ mole ratios.

In the Raman spectrum (figure 7), the peak nearing $410 \mathrm{~cm}^{-1}$ is the bending vibration peak of $\left[\mathrm{PO}_{4}\right]^{3-}$; the peak ranging from 1059 to $1064 \mathrm{~cm}^{-1}$ is the $\left[\mathrm{PO}_{4}\right]^{3-}$ asymmetric stretching vibration absorption peak; the peak ranging from 513 to $522 \mathrm{~cm}^{-1}$ is the $\left[\mathrm{PO}_{4}\right]^{3-}$ asymmetric bending vibration peak and the peak nearing $923 \mathrm{~cm}^{-1}$ is the symmetrical stretching vibration peak of $\left[\mathrm{H}_{2} \mathrm{PO}_{4}\right]^{-}[18,19]$. There are

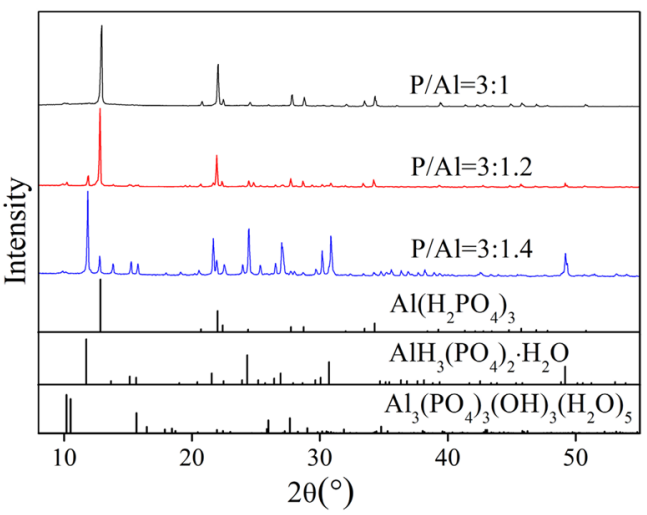

Figure 8. Powder XRD pattern of aluminium phosphate with different $\mathrm{P} / \mathrm{Al}$ ratios.

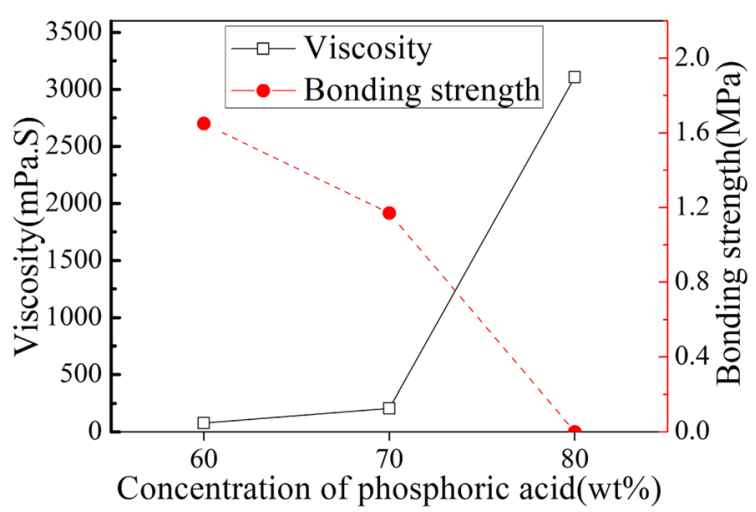

Figure 9. Viscosity and bonding strength with the concentration of phosphoric acid.

monomers or complexes of anionic $\left[\mathrm{H}_{2} \mathrm{PO}_{4}\right]^{-}$in aluminium phosphate solution. With $\left[\mathrm{H}_{2} \mathrm{PO}_{4}\right]^{-}$gradually moving from the monomers to the complexes, the symmetrical stretching vibration peak of $\left[\mathrm{H}_{2} \mathrm{PO}_{4}\right]^{-}$shifts to the high-wavenumber $[20,21]$. In the Raman spectrum, the vibration peaks of aluminium phosphate solution with $\mathrm{P} / \mathrm{Al}=3: 1,3: 1.2$ and $3: 1.4$ correspond to 923,928 and $928 \mathrm{~cm}^{-1}$, respectively, indicating 
(a)

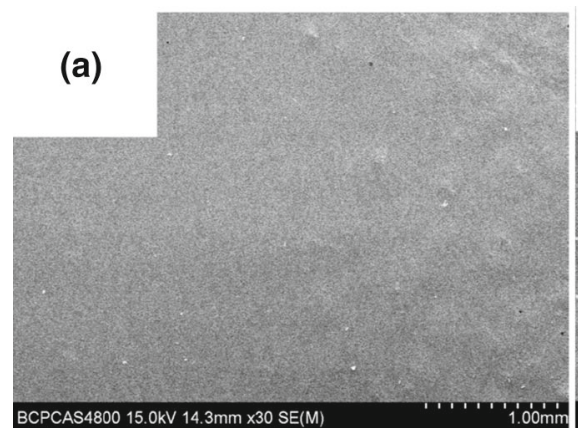

(b)

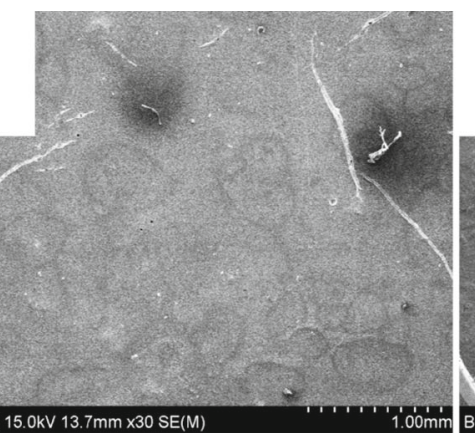

(c)

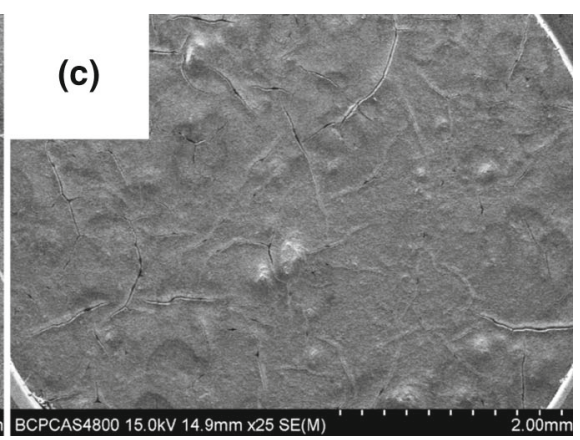

Figure 10. SEM images of coatings with different concentrations of phosphoric acid: (a) $60 \%$, (b) $70 \%$ and (c) $80 \%$.

that with an increase in the aluminium content, the degree of polymerization of the aluminium phosphate binder increased. At $\mathrm{P} / \mathrm{Al}=3: 1.4$, the peak at $968 \mathrm{~cm}^{-1}$ is clearly observed in Raman spectra, which belongs to the $\left[\mathrm{PO}_{4}\right]^{3-}$ symmetric stretching vibration [19]. This peak does not appear in the binder at $\mathrm{P} / \mathrm{Al}=3: 1$ and $3: 1.2$, indicating that there is more anionic $\left[\mathrm{PO}_{4}\right]^{3-}$ content in the binder at $\mathrm{P} / \mathrm{Al}=3: 1.4$.

The tests of the bonding strength of the coating show that the bonding effect of the coating at $\mathrm{P} / \mathrm{Al}=3: 1$ is better. Some studies point out that $\mathrm{Al}\left(\mathrm{H}_{2} \mathrm{PO}_{4}\right)_{3}$ was the best binder component [22]. By X-ray diffraction (XRD) phase analysis (figure 8), it was found that the only $\mathrm{Al}\left(\mathrm{H}_{2} \mathrm{PO}_{4}\right)_{3}$ crystal was obtained after curing at $\mathrm{P} / \mathrm{Al}=3: 1$. The diffraction peak of $\mathrm{AlH}_{3}\left(\mathrm{PO}_{4}\right)_{2} \cdot \mathrm{H}_{2} \mathrm{O}$ and the weakness peak of $\mathrm{Al}_{3}\left(\mathrm{PO}_{4}\right)_{3}(\mathrm{OH})_{3}\left(\mathrm{H}_{2} \mathrm{O}\right)_{5}$ appear in the diffraction pattern besides $\mathrm{Al}\left(\mathrm{H}_{2} \mathrm{PO}_{4}\right)_{3}$ at $\mathrm{P} / \mathrm{Al}=3: 1.2$. When $\mathrm{P} / \mathrm{Al}=3: 1.4$, the diffraction peak of $\mathrm{AlH}_{3}\left(\mathrm{PO}_{4}\right)_{2} \cdot \mathrm{H}_{2} \mathrm{O}$ is obvious, while the diffraction peak of $\mathrm{Al}_{3}\left(\mathrm{PO}_{4}\right)_{3}(\mathrm{OH})_{3}\left(\mathrm{H}_{2} \mathrm{O}\right)_{5}$ is even weaker. The results of XRD analysis shows that there are differences in the compositions of aluminium phosphate at different $\mathrm{P} / \mathrm{Al}$ mole ratios, and single $\mathrm{Al}\left(\mathrm{H}_{2} \mathrm{PO}_{4}\right)_{3}$ is formed when $\mathrm{P} / \mathrm{Al}=$ $3: 1$. When $\mathrm{P} / \mathrm{Al}=3: 1.2$ and $3: 1.4$, parts of the anions in the aluminium phosphate binder are present as $\left[\mathrm{PO}_{4}\right]^{3-}$. These results are consistent with the results of Raman analysis.

\subsection{Effect of concentration on viscosity and bonding strength}

Figure 9 shows the change in viscosity and bonding strength of coating with the concentration of phosphoric acid. As the concentration of phosphoric acid increases, the viscosity of the prepared aluminium phosphate binder increases, while the bonding strength of the coating decreases significantly. Figure 10 shows the SEM images of coatings with different concentrations of phosphoric acid. It can be found that as the moisture in the adhesive decreases and the viscosity increases, the crack on the surface of the cured coating gradually increases. The presence of cracks will adversely affect the bond strength of the coating. Among them, the coating with the phosphoric acid concentration of $80 \mathrm{wt} \%$ falls off during the curing process.

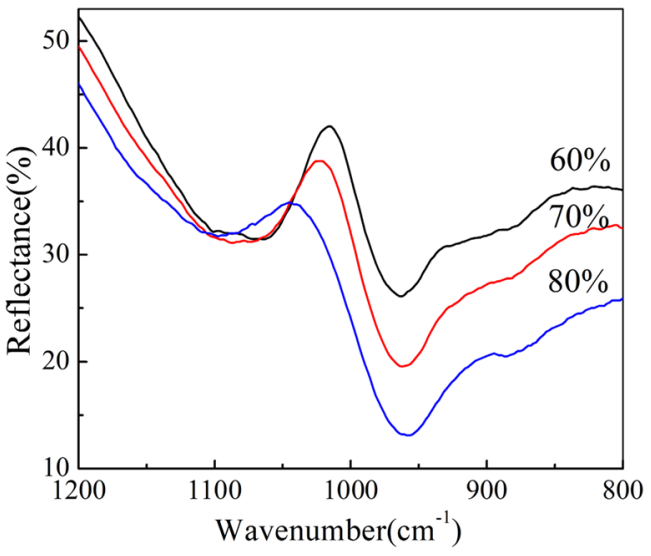

Figure 11. FT-IR spectra of the aluminium phosphate binder with different concentrations of phosphoric acid.

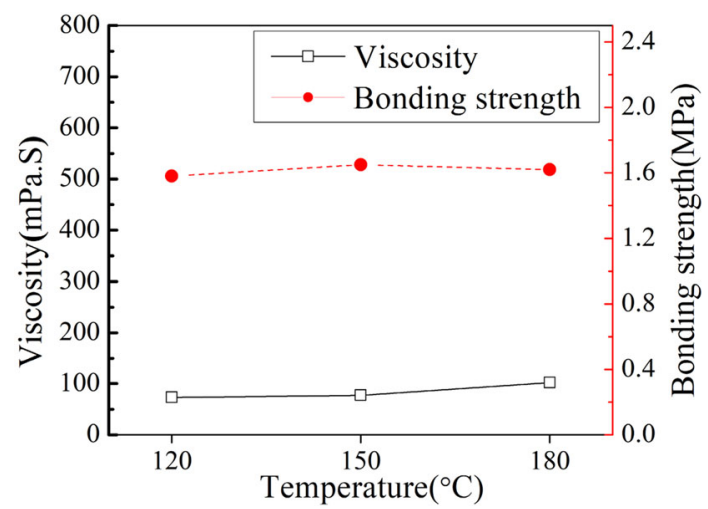

Figure 12. Viscosity and bonding strength with different reaction temperatures.

Figure 11 shows the FT-IR spectra of the aluminium phosphate binder prepared with the different concentrations of phosphoric acid. It can be seen that the intensity of the absorption peak of the vibration of the $\mathrm{P}-\mathrm{O}-\mathrm{P}$ bond nearing $960 \mathrm{~cm}^{-1}$ increases with an increase in the concentration, indicating that the number of $\mathrm{P}-\mathrm{O}-\mathrm{P}$ bonds in the binder with a high-concentration is larger. In addition, it is found that the absorption peak of the symmetrical stretching 
(a)

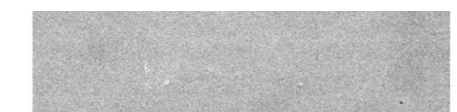

(b)

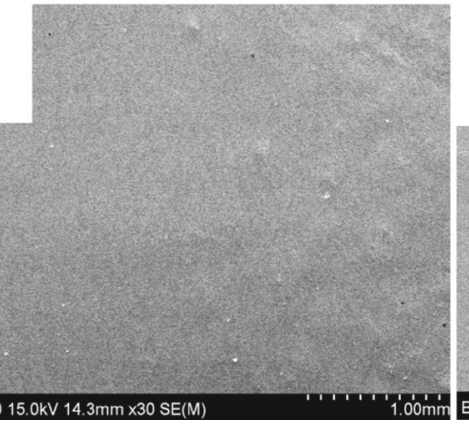

(c)

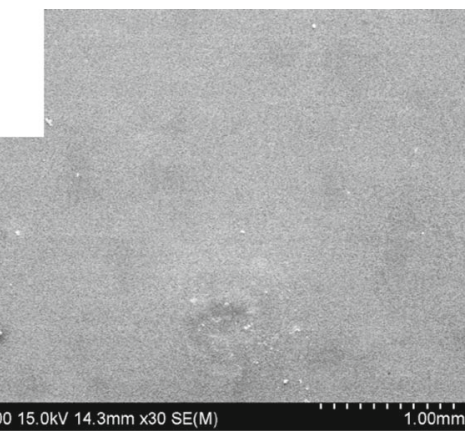

Figure 13. SEM images of coatings with different reaction temperatures: (a) $120^{\circ} \mathrm{C},(\mathbf{b}) 150^{\circ} \mathrm{C}$ and $(\mathbf{c}) 180^{\circ} \mathrm{C}$.

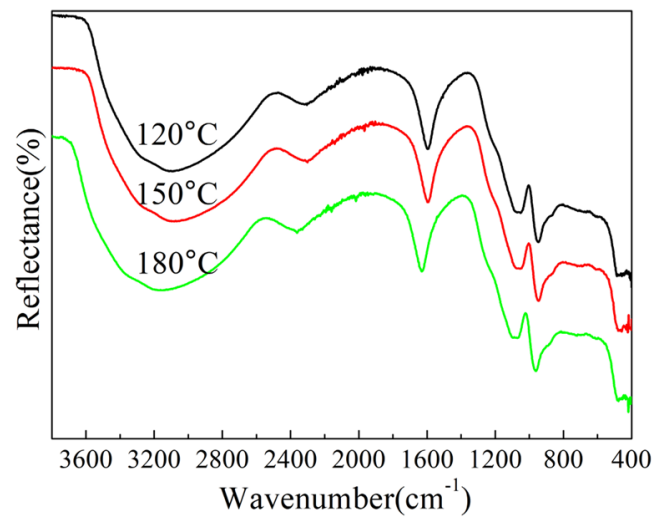

Figure 14. FT-IR spectra of the aluminium phosphate binder with different reaction temperatures.

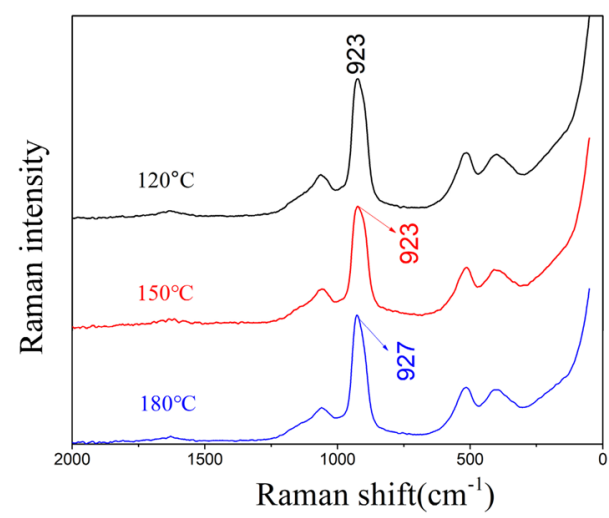

Figure 15. Raman spectra of the aluminium phosphate binder with different reaction temperatures.

vibration of $\mathrm{O}-\mathrm{P}-\mathrm{O}$ (in the range of $1050-1100 \mathrm{~cm}^{-1}$ ) shifts to higher wavenumbers with a decrease in the concentration. The frequency of the stretching vibration of $\mathrm{P}-\mathrm{O}$ in the different degrees of polymerization of $\mathrm{P}-\mathrm{O}$ tetrahedron groups increases with an increase in polymerization degree, so $\mathrm{P}-\mathrm{O}$ tetrahedra in a high-concentration of aluminium phosphate solution will exist in a larger polymeric structure, which is one of the reasons that the viscosity of the solution increases with an increase in

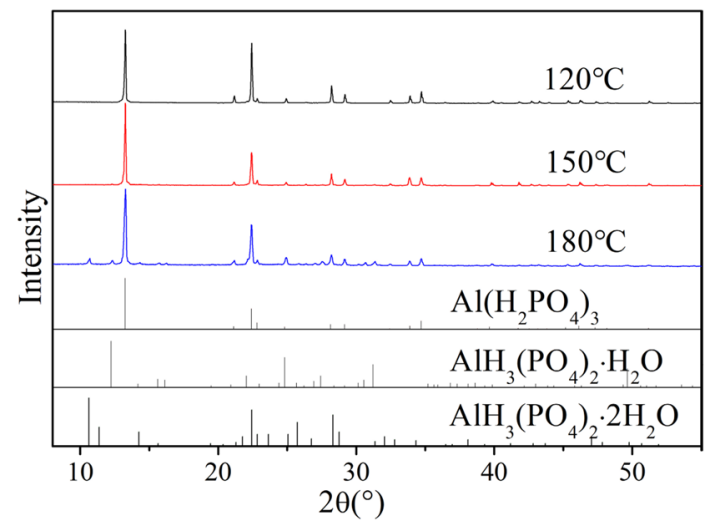

Figure 16. Powder XRD pattern of aluminium phosphate with different reaction temperatures.

concentration. In addition, a higher concentration of the aluminium phosphate binder contains a more viscous substance in per unit volume, which also contributes to the increased viscosity.

The experimental results showed that the bonding strength of the coating decreases with an increase in the degree of polymerization of the binder instead of being increased. Considering with the process analysis of the coating preparation, the defects of coating exist at the beginning of coating. This is because it is difficult for the phosphate binder to be a uniform film due to the high-viscosity of the aluminium phosphate binder with a high-concentration. In addition, the heat generated by the chemical reaction of the binder and $\mathrm{MgO}$ promotes the evaporation of water and increases the viscosity. Subsequently, the construction becomes more difficult. Finally, the coating structure is loose, the bonding effect between the coating and the substrate is unsatisfactory, and even the coating completely falls off.

\subsection{Effect of reaction temperature on viscosity and bonding strength}

As shown in figure 12, the change in the viscosity of the aluminium phosphate binder slightly increases with an increase in the preparation temperature in the range of $120-180^{\circ} \mathrm{C}$, 
and the change in the bonding strength of the coating is not obvious. It can be found from SEM in figure 13 that different coatings are all self-levelling and have a smooth surface, which makes them have good bonding strength.

In the range of $120-180^{\circ} \mathrm{C}$, the FT-IR spectra of aluminium phosphate binders prepared at different temperatures are basically the same as illustrated in figure 14. The Raman spectrum shows that the vibrational peak of $\left[\mathrm{H}_{2} \mathrm{PO}_{4}\right]^{-}$symmetric stretching moves from $923\left(120\right.$ and $\left.150^{\circ} \mathrm{C}\right)$ to $927 \mathrm{~cm}^{-1}$ $\left(180^{\circ} \mathrm{C}\right)$ as shown in figure 15 , predicating that the viscosity of the binder slightly increases with an increase in temperature due to the fact that the increase in the reaction temperature is conducive to the full reaction, which increases the degree of polymerization of the binder. It was found from the XRD patterns as shown in figure 16 that the prepared aluminium phosphate binder exclusively contains $\mathrm{Al}\left(\mathrm{H}_{2} \mathrm{PO}_{4}\right)_{3}$ at the reaction temperatures of 120 and $150^{\circ} \mathrm{C}$. $\mathrm{Al}\left(\mathrm{H}_{2} \mathrm{PO}_{4}\right)_{3}$ is still the main product when the temperature reaches $180^{\circ} \mathrm{C}$. However, the presence of a small amount of $\mathrm{AlH}_{3}\left(\mathrm{PO}_{4}\right)_{2} \cdot \mathrm{H}_{2} \mathrm{O}$ or $\mathrm{AlH}_{3}\left(\mathrm{PO}_{4}\right)_{2} \cdot 2 \mathrm{H}_{2} \mathrm{O}$ has an insignificant effect on the bonding strength. It could be considered that in the temperature range from 120 to $180^{\circ} \mathrm{C}$ in this experiment, the main component of the binder is $\mathrm{Al}\left(\mathrm{H}_{2} \mathrm{PO}_{4}\right)_{3}$ when the $\mathrm{P} / \mathrm{Al}$ mole ratio is $3: 1$. Thus the changes of binder viscosity and coating bonding strength are not obvious.

\section{Conclusion}

In this paper, a coating is prepared on the surface of carbon fibre-reinforced epoxy resin composites at low-temperature using an aluminium phosphate binder, the curing agent $\mathrm{MgO}$ and the filler $\mathrm{ZrO}_{2}$ in a certain proportion by the brushing method. The aluminium phosphate binders using $\mathrm{H}_{3} \mathrm{PO}_{4}$ and $\mathrm{Al}(\mathrm{OH})_{3}$ as the raw materials were synthesized by controlling the three process parameters: the concentration of phosphoric acid reactants, the $\mathrm{P} / \mathrm{Al}$ mole ratio and the reaction temperature. The experimental results show that the concentration of phosphoric acid, the $\mathrm{P} / \mathrm{Al}$ mole ratio and the reaction temperature could have effects on the viscosity of the aluminium phosphate binder and the bonding strength of the coating.

(1) As the P/Al mole ratio decreases, the degree of polymerization of the aluminium phosphate binder increases, the viscosity of the binder increases and the bonding strength of the coating decreases. When $\mathrm{P} / \mathrm{Al}=3: 1$, the product of the reaction is $\mathrm{Al}\left(\mathrm{H}_{2} \mathrm{PO}_{4}\right)_{3}$ which has the best bonding properties.

(2) As the concentration of the reactant phosphoric acid solution increased in the range of $60-80 \%$, the number of viscous molecules per unit volume in the aluminium phosphate binder increased, the degree of polymerization of the $\mathrm{P}-\mathrm{O}$ groups increased and the viscosity increased. Since the high-concentration of the aluminium phosphate binder has high-viscosity, it is difficult to construct a uniform film, and the coating has defects during the coating process, leading to an unsatisfactory binding effect. Consequently, the bonding strength of the coating showed a decreasing trend as the concentration increased.

(3) In the temperature range from 120 to $180^{\circ} \mathrm{C}$, an increase in the reaction temperature will increase the degree of polymerization of the aluminium phosphate binder and increase the viscosity slightly. Because the main components of the binder is $\mathrm{Al}\left(\mathrm{H}_{2} \mathrm{PO}_{4}\right)_{3}(\mathrm{P} / \mathrm{Al}=3: 1)$, the variation of the strength of the coating is not obvious when the preparation temperature changes.

(4) As the viscosity increases, the flatness of the coating prepared by the aluminium phosphate adhesive decreases, and the cracks are easily generated after curing, thereby lowering the bonding strength of the coating. The best preparation process of aluminium phosphate adhesive is when $\mathrm{P} / \mathrm{Al}=3: 1$, phosphoric acid concentration is $60 \%$ and the reaction temperature is $120^{\circ} \mathrm{C}$.

\section{Acknowledgements}

The use of the National Key Laboratory of Science and Technology on Armor and Anti-armor Materials at BIT is gratefully acknowledged. The authors would like to acknowledge the Liushan Jiang and Jinpeng Zhu for their contributions in polishing this paper.

\section{References}

[1] Choi B and Choi B 2015 Compos. B Eng. 8242

[2] Soutis C 2005 Prog. Aerosp. Sci. 41143

[3] Langemeier P and Scheuer C 2010 Reinf. Plast. 5436

[4] Chen D, He L and Shang S 2003 Mater. Sci. Eng. A 34829

[5] Bakunov V S and Shayakhmetov U S 2007 Refract. Ind. Ceram. 4898

[6] Hao R, Liu J, Xue D, Guo A, Hou Z and Min W 2013 Int. J. Appl. Ceram. Technol. 10978

[7] Maz N S B 2010 Refract. Ind. Ceram. 5139

[8] Fang K, Chen Y F, Zhang S C, Sun H R, Wang G H and Sun X K 2016 Key. Eng. Mater. 697441

[9] Hipedinger N E, Scian A N and Aglietti E F 2002 Cem. Concr. Res. 32675

[10] Pirogov Y A, Soloshenko L N and Kvasman N M 1987 Refractories 28117

[11] Fernando J A and Chung D D L 2001 J. Mater. Sci. 365079

[12] Kim D P, Myung H S and Rho J S 2003 Compos. Sci. Technol. 63493

[13] Vippola M, Ahmaniemi S, Keränen J, Vuoristo P, Lepistö T, Mäntylä T et al 2002 Mater. Sci. Eng. A 3231

[14] He L, Chen D and Shang S 2004 J. Mater. Sci. 394887

[15] Chiou J M and Chung D D L 1993 J. Mater. Sci. 281435

[16] Aguiar H, Serra J, Gonzlez P and Len B 2009 J. Non-Cryst. Solids $\mathbf{3 5 5} 475$

[17] Moustafa Y M and El K 1998 J. Non-Cryst. Solids 240144 
[18] Chahine A, Et-Tabirou M and Pascal J L 2004 Mater. Lett. 58 2776

[19] Chang W B, Jin Z Z and Zou X W 1991 Phys. Lett. A 159 361
[20] Berglund K A, Larson M A, Cerreta M K and Mcmahon P M 1986 Appl. Spectrosc. 40282

[21] Liu G and Wu G 1988 Spectrochim. Acta A 441007

[22] Kingery W D 1950 J. Am. Ceram. Soc. 33242 